\title{
Critical Thinking and Argumentative Writing: Inspecting the Association among EFL Learners in China
}

\author{
Zhengwei Pei ${ }^{1}$, Chaoqun Zheng ${ }^{1}$, Meng Zhang ${ }^{1} \&$ Fangzhou Liu ${ }^{1}$ \\ ${ }^{1}$ School of Foreign Studies, Nanjing Agricultural University, Nanjing, China \\ Correspondence: Zhengwei Pei, School of Foreign Studies, Nanjing Agricultural University, 1 Weigang, \\ Nanjing, Jiangsu 210095, China. Tel: 86-25-84395755. E-mail: wei@njau.edu.cn
}

Received: August 10, 2017 Accepted: September 2, 2017 Online Published: September 4, 2017

doi: 10.5539/elt.v10n10p31 URL: http://doi.org/10.5539/elt.v10n10p31

\begin{abstract}
Nurturing critical thinking (CT) has been acknowledged as a core objective of tertiary education, and drawn attention from academia of teaching English as a Foreign Language (EFL) in China. The thrust of the present study was to determine the association between CT and EFL argumentative writing among Chinese undergraduates. To this end, 110 English majors across three grades at two universities were conveniently selected and given the critical thinking skills (CTS) test and EFL argumentative writing test. The results of this study indicated that undergraduate English majors in China did not possess strong CTS. Though their CTS was not found to be significantly correlated with EFL argumentative writing performance, textual analysis of typical essays showed that strong-CTS learners outperformed weak-CTS ones in relevance, clarity, logicality, profundity and flexibility of argumentative writing. The obtained results suggest a need to integrate CT into EFL writing instruction.
\end{abstract}

Keywords: critical thinking skills, EFL argumentative writing performance, English majors, textual analysis

\section{Introduction}

As societies become more information rich and technologically complex, the global job-market sets a higher demand for educational institutions and calls for a shift from disseminating knowledge to developing transferable skills pivotal to competitiveness and employability of graduates. Among these transferable skills is critical thinking (hereafter CT) (Stephenson \& Sadler-McKnight, 2016). CT has been widely promoted over recent decades in higher education by many Asian countries such as Singapore and Malaysia (Luk \& Lin, 2015).

In July, 2010 the Chinese Ministry of Education issued The National Plan for Medium and Long-term Education Reform and Development (2010-2020), placing a priority on the development of students' CT and innovative ability. Cultivation of CT has since been considered as one of the core objectives of tertiary education, and has grabbed attention from the Chinese academia of teaching English as a Foreign Language (EFL). After reviewing the CT-related literature published in nine CSSCI ${ }^{1}$ foreign language journals from 2000 to 2015, Yang and Ren (2016) reported that among the total of 51 publications, the number of related journal articles increased substantially after issuance of the national plan. Despite the fast-growing research, the dearth of empirical studies linking CT to EFL performance of Chinese EFL learners is evident. This study aims to bridge the gap by measuring the association between CT and EFL writing among a group of university students in China.

\section{Research background}

\subsection{Critical Thinking of English Majors in China}

As a term with multiple definitions, CT broadly comprises skills and disposition. Critical thinking skills (CTS) are concerned with cognitive skills such as interpretation, analysis, evaluation, explanation, inference, and self-regulation, while critical thinking disposition (CTD) relates to the affective domain, including inquisitiveness, systematicity, analyticity, truth-seeking, open-mindedness, self-confidence, and maturity (N. C. Facione, P. A. Facione, \& Sánchez, 1994).

In China, English professor Huang (1998) was the first to point out the absence of CT among undergraduates majoring in English and other foreign languages based on his observation of students' failure to pose questions in class, articulate ideas in writing, and argue in discussions or debates. Gradually, foreign language majors in Mainland China seem to be notorious for the stereotype of CT-deprivation, characterized by refusal to think 
deeply and deficiency in higher-order skills. To empirically test whether English majors really suffer from that syndrome or not, Wen and her collaborators conducted two large-scale studies and documented their findings in Wen, Zhang and Sun (2014) showing that the CTS and CTD of English majors were not inferior to those of liberal arts majors and sciences majors and that foreign language majors' deficiency in CT was just a pseudo-proposition lacking any empirical support. Unlike Wen et al. (ibid), where the CT instruments developed by Wen and her research team for Chinese university students were employed, several other studies using western instruments yielded less optimistic results. Cao and Wu's (2014) survey of 20 junior English majors using California Critical Thinking Skills Test (CCTST) and California Critical Thinking Disposition Inventory (CCTDI) indicated that students' CTS was at a low or medium level and their CTD was unstable. Mu (2016) investigated 73 senior English majors using the Chinese version of CCTDI and found them to be weak in CTD.

Given the lack of empirical evidence regarding the general situation of CT abilities of foreign language majors, this study examined the level of CTS of English majors in two Chinese universities to assess the truthfulness of the $\mathrm{CT}$ absence of English majors.

\subsection{Critical Thinking and EFL Argumentative Writing}

Writing an argumentative essay is required by international high-stakes tests like TOEFL and IELTS, and also by Test for English Majors (TEM), a criterion-referenced English language test specifically targeted at university undergraduates majoring in English Language and Literature in China (Jin \& Fan, 2011). EFL argumentative writing is not only an organizational process of words, phrases and sentences but also a complex process that involves grasping the topic, developing the statement, organizing a coherent discourse and putting ideas into writing. It calls for intellectual capacity for thinking critically, thus a good piece of writing should reflect the aspects of CT to some extent. However, to the best of our knowledge, merely a few studies have explored the relation between CT and EFL writing performance of EFL learners in Chinese universities. For example, Yang and Wu's study (2016) with 94 non-English-major postgraduates found CTD significantly correlated with students' writing performance judged against the criteria of language, content and material in varying degrees. In $\mathrm{Mu}$ (2016), senior English majors took part in a survey of CTD and their essays were assessed against the criteria on CT quality. They were found to have CT problems in precision, depth and rhetorical appropriateness in English argumentative writing. Additionally, Qian (2015) investigated the relationship between 80 junior English majors' EFL argumentative writing and CTS tested with the Watson-Glaser Critical Thinking Appraisal (WGCTA) and discovered their significant correlation.

To advance the CT-relevant empirical research in EFL writing, the study would systematically explore if in China undergraduate English majors' CTS and EFL argumentative writing performance are associated or not. We focused on CTS because it can be objectively measured and its cultivation is a principle of university education (Pithers \& Soden, 2000). Hopefully, the findings will unveil the relationship between CTS and EFL argumentative writing and provide insights into EFL writing teaching in China and similar EFL contexts.

\section{Methodology}

\subsection{Research Questions}

Three questions guided the inquiry of this study: 1) What is the level of CTS among English majors in Chinese universities? Are there any differences across grades? 2) What is the relationship between English majors' CTS and their EFL argumentative writing performance? 3) What differences do English majors at varying levels of CTS exhibit in their EFL writing performance?

\subsection{Participants}

Initially, 132 English majors selected via convenience sampling from two national key universities in Nanjing, China, participated in the study. 22 were later excluded from analysis because 18 students failed to complete the CTS test, and four were suspected of copying their essays from the Internet instead of composing them in person on the EFL argumentative writing test. This observation will be explained in the following section together with the CTS test. The valid sample comprised 110 English majors aged 17 to $23\left(\mathrm{M}_{\text {age }}=20\right.$ years $), 88$ of them being females $(80 \%)$. They were almost evenly distributed across three grades (38 freshmen, $34.5 \%$; 37 sophomores, $33.6 \%$; 35 juniors, 31.8\%); 61 (55.5\%) were from Nanjing Agricultural University (NAU), while 49 (44.5\%) were from Nanjing University of Science and Technology (NUST).

\subsection{Instruments}

\subsubsection{Critical Thinking Skills Test}

As one of the popular instruments to measure CTS, the WGCTA is most often used in post-secondary education 
to assess general reasoning skills rather than the discipline-specific thinking. It is considered reliable and valid for testing CT among different academic groups (Behar-Horenstein \& Niu, 2011; Wangensteen et al., 2010). It is composed of five subscales: inference, recognition of assumptions, deduction, interpretation, and evaluation of arguments. The Chinese version of WGCTA (CWGCTA), with demonstrated reliability, validity and applicability for Chinese students as reported by Zhu (2002) as well as Zhu and Shen (2004), was adopted in this study.

To reduce the administration time, the 80 -item CWGCTA was subjected to item analysis following a pilot study with 65 freshmen and sophomores at NAU. Item analysis included checking the item facility (IF) and item discrimination (ID). IF examines the percentage of students who correctly answered a given item. IF is calculated by adding the number of students who correctly answered a particular item and dividing that sum by the total number of students who took the test. ID indicates the degree to which an item separates the students who performed well (the upper group) from those who did poorly on the test as a whole (the lower group). To calculate ID, the IF for the lower group is subtracted from the IF for the upper group on each item (Brown, 2006, pp. 66-69). After item analysis, 50 items falling within acceptable ID and IF ranges were retained and constituted the CTS test for our formal study whereby the calculated reliability was 0.69 using Cronbach's alpha coefficient. Table 1 displays a comparison between the original and revised forms of CWGCTA in terms of their item number, and the descriptions of five CTS subscales derived from Watson and Glaser (2008, pp. 3-4).

Table 1. Comparison between two forms of CWGCTA in item number and the descriptions of CTS subscales

\begin{tabular}{|c|c|c|c|}
\hline \multirow[t]{2}{*}{ CTS subscales } & \multirow[t]{2}{*}{ Descriptions } & \multicolumn{2}{|c|}{ Item number } \\
\hline & & $\begin{array}{l}\text { Original } \\
(\mathrm{N}=80)\end{array}$ & $\begin{array}{l}\text { Revised } \\
(\mathrm{N}=50)\end{array}$ \\
\hline Inference & $\begin{array}{l}\text { Discriminating among degrees of truth or falsity of inferences } \\
\text { drawn from given data }\end{array}$ & 16 & 14 \\
\hline $\begin{array}{l}\text { Recognition of } \\
\text { assumptions }\end{array}$ & $\begin{array}{l}\text { Recognizing unstated assumptions or presuppositions in given } \\
\text { statements or assertions }\end{array}$ & 16 & 9 \\
\hline Deduction & $\begin{array}{l}\text { Determining whether certain conclusions necessarily follow from } \\
\text { information in given statements or premises }\end{array}$ & 16 & 8 \\
\hline Interpretation & $\begin{array}{l}\text { Weighing evidence and deciding if generalizations or conclusions } \\
\text { based on the given data are warranted }\end{array}$ & 16 & 12 \\
\hline $\begin{array}{l}\text { Evaluation } \\
\text { arguments }\end{array}$ & $\begin{array}{l}\text { Distinguishing between arguments that are strong and relevant and } \\
\text { those that are weak or irrelevant to a particular issue }\end{array}$ & 16 & 7 \\
\hline
\end{tabular}

\subsubsection{EFL Argumentative Writing Test}

This test assesses participants' EFL argumentative writing performance. The topic and directions for participants were as follows: Do you agree or disagree with the following statement? Parents are the best teachers. Write an argumentative essay of at least 450 words, and use specific reasons and examples to support your answer. Its word limit exceeded that for TEM Band-4 (about 200 words) so that participants were allowed more space to express themselves.

The writing topic was selected for its familiarity and openness. It was familiar to Chinese students, as they were acquainted with the Chinese proverb 养不教父之过 from a Confucian primer for children Three-Character Classic, which literally means "to feed without teaching is the father's fault" and underscores the parental role in educating the young. The quality of critical thought depends on topic familiarity. A familiar topic typically generates better CT, according to Stapleton (2001). Meanwhile, the topic is controversial and thus open to discussion. Parents are beyond doubt the first teachers for their children, but are not necessarily the best teachers. Since there is no fixed answer to the topic, participants could articulate their viewpoints from more than one perspective. This untimed writing test was designed this way because a familiar writing topic without time constraint enables students to challenge authorities and think creatively (Liu, 2005).

\subsection{Data Collection}

Data were collected during the spring semester of 2016. Prior to this, the participants were informed of the research purpose and assured of the confidentiality of their data. The CWGCTA was administered to the participants during regular lecture periods and took up to 25 minutes to complete. At the conclusion of testing, 
all the test papers were returned. The EFL writing test was taken individually by participants after class. One week after the writing assignment, the participants submitted electronic essays to their EFL teachers who assisted us in collecting data. Essays were then scrutinized. Those that did not meet the word limit requirements or were suspected of having been copied from the Internet were excluded from subsequent data analysis.

\subsection{Data Analysis}

Grading of the CWGCTA papers was done against the key in Zhu (2002). Each correct answer awarded 1 point, the total score was 50, a summation of the separate scores on five subscales. Though argumentative writing is tested on TEM, writing performance is always judged against the criteria of content (relevance and completeness) and specifics of language (grammar, vocabulary, and appropriateness) (Jin \& Fan, 2011). Few scoring standards were laid out to evaluate CT quality in written discourse. To assess CT in EFL argumentative writing, Wen (2012) proposed a five-category model encompassing relevance, clarity, logicality, profundity, and flexibility. Built upon her ground-breaking work, we developed the scoring rubric in Table 2.

Table 2. The scoring rubric used in this study

\begin{tabular}{ll}
\hline Categories & Descriptions \\
\hline Relevance & $\begin{array}{l}\text { Is the essay related to the writing topic? Does the participant choose a proper writing style of } \\
\text { argumentation? }\end{array}$ \\
Clarity & $\begin{array}{l}\text { Does the participant make clear his/her thesis and sub-theses? } \\
\text { Logicality }\end{array}$ \\
& $\begin{array}{l}\text { Does the participant demonstrate a logical argument by bringing thoughts and sentences } \\
\text { together into some order? }\end{array}$ \\
Profundity & $\begin{array}{l}\text { Does the participant provide sufficient arguments to support his/her sub-theses and ideas? } \\
\text { Flexibility }\end{array}$ \\
& $\begin{array}{l}\text { Does the participant bring in ingenious ideas and argue for his/her thesis and sub-theses from } \\
\text { multiple perspectives? }\end{array}$ \\
\hline
\end{tabular}

To prevent subjectivity and bias while evaluating the categories indicative of CT quality in EFL writing, three EFL teachers at the universities where the study was launched rated student essays independently according to the descriptions for each of the categories in Table 2 . In rating each essay, they holistically evaluated every category along five levels $(1=$ poor, $3=$ average, $5=$ excellent $)$, hence the total writing score was 25 . To familiarize themselves with the scoring procedure, they came together to study the scoring rubric and practiced rating 40 essays before formal work. In formal rating, inter-rater reliability statistics (Cronbach's Alpha) for the categories were: 0.64 (relevance), 0.70 (clarity), 0.67 (logicality), 0.60 (profundity), and 0.61 (flexibility), resulting in an average reliability of 0.64 .

After the participants' CWGCTA papers and EFL argumentative essays were rated, their scores were keyed into SPSS 16.0 for descriptive analysis, one-way ANOVA, and correlation analysis in response to Research Questions 1 and 2. To answer Question 3, a textual analysis of typical essays was made to detect possible differences between students of high and low CTS levels in EFL writing performance, with Microsoft Office Excel 2010 utilized as a supplement.

\section{Results and Discussion}

\subsection{Level of CTS among English Majors in Chinese Universities and across-Grade Differences}

Descriptive statistics demonstrated that the participants' CTS scores varied from 19 to 43 ; $88 \%$ of the participants showed weak CTS $(<34)$; only $9 \%$ and $3 \%$ of them showed average $(34-40)$ and strong $(>40)$ CTS, referring to the standard set by Waston and Glaser to differentiate levels of CTS (cited in Qian, 2015). This result echoes Qian (2015) where 39\% of the participants had moderate CTS and 43\% had weak or little CTS. Different from Oian (2015) and the present study, Cao and Wu (2014) used CCTST to measure CTS, and also found that English majors were not strong in CTS and that their scores fell into low and moderate ranges.

When comparing the CTS by grade, the total CTS scores for Grades One, Two, Three were 30.18, 29.54 and 30.20 respectively; no statistical differences across grades were observed, which was verified by the follow-up one-way ANOVA which revealed no significant difference among the three grades in their total CTS scores. In this study the total CTS score obtained on the CWGCTA was interpreted, because a meta-analytic review by Bernard et al. (2008) recommended that it would be better to treat the scale as a measure of general CT 
competency rather than interpret subscales individually.

In a word, the state quo of CTS of English majors in Chinese universities is not optimistic. Our finding supports truthfulness of the syndrome of $\mathrm{CT}$ absence among foreign language majors. To decide whether or not students lack a demonstration of CTS is generally dependent on a set of behaviors which are assumed to reflect CTS; these behaviors often include overt questioning or debating of ideas in the classroom. Often teachers observe these behaviors and then infer whether their students demonstrate CT. It is from his observation of English majors' behaviors of this sort that Huang (1998) lamented over their lack of CT, which is largely due to the improper curricular design and teaching methods. The current teaching syllabus and methods for English majors focus on improving language skills through imitation, rote memorization, and repeated drilling rather than formulating systematic English knowledge and promoting thinking and innovative abilities. Without a solid system of English knowledge established through systematic disciplinary training, it is impossible for English majors to activate systematicity of knowledge they have stored in Chinese to think critically and fully express in English (Qu, 2015). While enhancing language skills per se is imperative and impeccable, neither EFL teaching contents nor methods are cognitively challenging enough to promote the development of CT among undergraduates (Wen et al., 2010). To rectify the situation, teaching activities empowering students to question, analyze, discuss and solve problems should be incorporated into language classrooms.

\subsection{Correlation between English Majors' CTS and EFL Argumentative Writing Performance}

The Pearson correlation coefficient between participants' CTS and writing scores was $0.043(\mathrm{p}=0.657)$, insignificant at 0.05 level. This result is not in parallel with the significant correlation documented by Qian (2015). For one thing, the study failed to control participants' EFL proficiency. In recent years, reviews and empirical studies have challenged the assertion that Asian students are deficient in CT because of cultural traditions; they have also argued that inadequate English proficiency is a factor hindering EFL learners from thinking critically. Tian and Low (2011), for example, reviewed the published literature about Chinese students' CT performance at universities abroad and identified subject area knowledge and target language proficiency as two key debilitative factors. Lun, Fischer and Ward (2010) addressed whether there are differences in CTS between 102 Asian and 210 European students at a Western institution. They discovered that students' CT could predict their academic performance after controlling for the effects of English proficiency and general intellectual ability. In China, Gao (2015) testified that English proficiency is a crucial factor determining CTS of English majors. Forty English majors fell into two groups according to their English proficiency levels, and received writing and oral tests in English and Chinese. They were inadequate in English writing and speaking, but when both were done in Chinese they could easily display CT. Luk and Lin (2015) present two sets of discourse data showing how low-English-proficiency secondary students in Hong Kong conducted critical talk first within a group using Cantonese (L1), followed by a whole-class presentation in English. Discourse analysis of the criticality and elaborateness of the Cantonese and English utterances revealed the impact of linguistic proficiencies on CT performance of ESL learners. Unlike Qian (2015) who investigated junior English majors, we surveyed English majors across three grades; their heterogeneity and mixed EFL proficiency levels may have moderated the observed relationship between CTS and EFL writing performance.

For another, writing may not be simply equated with CT. Condon and Kelly-Riley (2004) in Washington State University examined students in the Writing Assessment Program. Surprisingly, they found an inverse relationship between their CT and writing ability. Despite the long-held belief that writing and thinking are inextricably linked, no or an inverse correlation between students' writing and CT scores indicates that writing acts as a vehicle for CT, but writing itself is not CT. Having students write does not automatically mean that they are engaged in thinking critically. In China EFL writing instruction always neglects honing student higher-order thinking, and EFL writing test intended for assessing sound writing abilities virtually requires no or superficial critical thought. When practicing EFL writing, Chinese students become accustomed to modeling their writing on fixed templates covering formulaic phrases rather than putting their ideas into writing.

\subsection{Differences between English Majors at High and Low Levels of CTS in EFL Argumentative Writing Performance}

Judging from descriptive data, the participants' EFL writing scores ranged from 9.67 to 24; mean EFL writing score was 17.75, higher than the passing cut-off score on a test. Mean scores for the five categories are presented in the descending order: relevance $=3.97$, clarity $=3.58$, logicality $=3.47$, flexibility $=3.40$, and profundity $=$ 3.35. This pattern coincides with what Wen and Liu (2006) discovered in their survey of 120 EFL essays composed by English majors across four grades, with students performing the best in relevance and not so well in profundity. 
For between-group comparisons, participants were divided into strong-CTS $(\mathrm{N}=34, \mathrm{M}=18.48)$, average-CTS $(\mathrm{N}=37, \mathrm{M}=17.34)$ and weak-CTS $(\mathrm{N}=39, \mathrm{M}=17.51)$ groups according to their CWGCTA scores. One-way ANOVA did not produce a significant difference among the groups $(F(2,107)=1.172, p=.314>.05)$. Nevertheless, the stronger the CTS, the stronger the EFL argumentative writing performance that was observed. In matters of the separate writing scores for five categories, the strong-CTS Group topped the list; the average-CTS Group outperformed the weak-CTS Group in logicality, profundity and flexibility, but performed worse than the latter in relevance and clarity (See Figure 1).

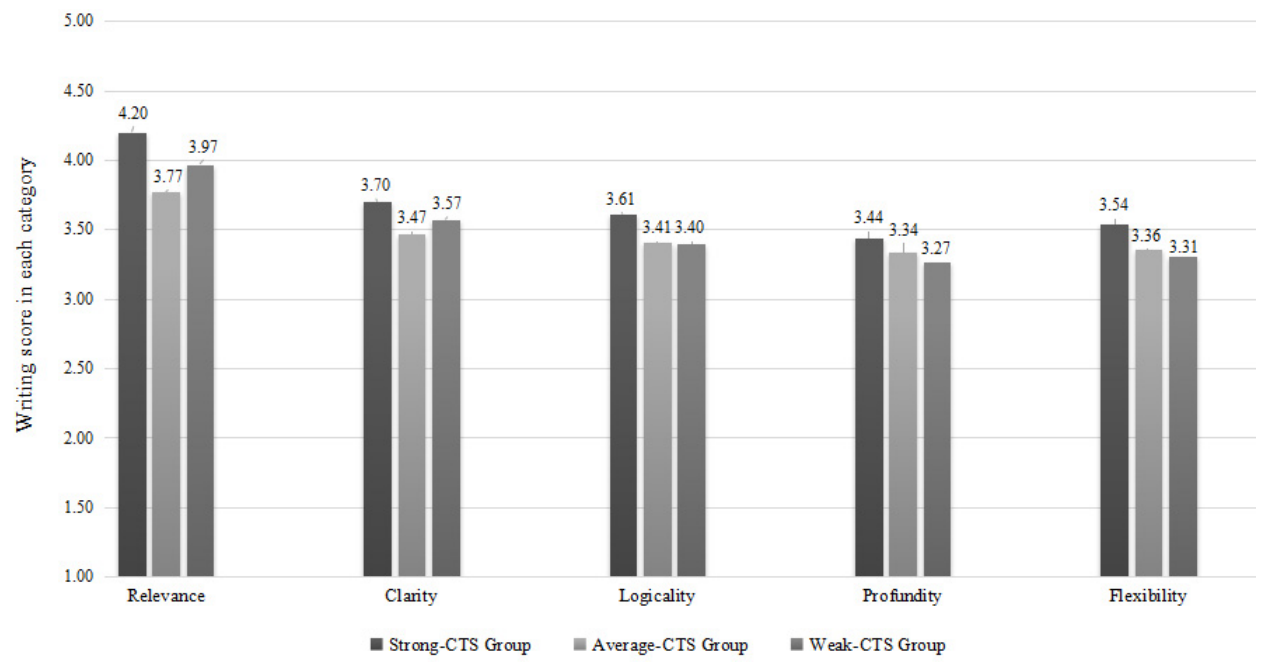

Figure 1. Between-group comparisons on total and separate EFL writing scores

Ahour and Golpour (2014) investigated the relationship between Iranian university EFL learners' CT levels and writing performance in descriptive and argumentative modes, with the Longman paper and pencil test administered to ensure the learner homogeneity. Their study revealed a statistically significant difference between high and low critical thinkers in their writing performance. Higher performing critical thinkers scored better than low critical thinkers in both modes of writing. To detect the potential differences in EFL argumentative writing among English majors, we textually analyzed the essays of 10 female participants, half with strong CTS and another half with weak CTS (Table 3). Observed differences in five categories follow.

Table 3. Information of the ten participants selected for textual analysis of their essays

\begin{tabular}{llllll}
\hline Strong CTS students & Grade & University & Weak CTS students & Grade & University \\
\hline Rose & Freshman & NUST & Canna & Freshman & NUST \\
Lily & Freshman & NUST & Ivy & Junior & NAU \\
Daisy & Junior & NAU & Iris & Junior & NAU \\
Violet & Junior & NAU & Clover & Junior & NUST \\
Jasmine & Junior & NUST & Lavender & Sophomore & NUST \\
\hline
\end{tabular}

Note: Pseudonyms are used to protect the student privacy.

\subsubsection{Relevance}

To achieve relevance, the writer needs to deconstruct the writing topic, grasp the connotation of its inclusive concepts, and judge the interrelationship among those concepts (Wen \& Liu, 2006). The writing topic of this study involved three concepts: parents, the best (not a common or good), and teachers. Understanding of teachers should not be restricted to those taking up a teaching job at school. Teachers referred broadly to those who play the role of an educator or a guidance provider, just as a proverb in The Analects of Confucius goes, 三 人行必有我师 which literally means “when I walk along with two others, I can always find teachers in them". 
The interrelationship of the three concepts was whether parents are the best teachers, which required the writer to state his or her viewpoint and support it with specific reasons and examples, implying adoption of an argumentative writing style.

The five strong-CTS students outperformed others in grasping key concepts and in connecting interrelationships. They all produced their writings in the proper form of argumentation. In the opening paragraph, Rose contended that parents are the best teachers and demonstrated her correct understanding of teachers by pointing out that they [teachers] include not only teachers at school, but also parents, friends, superiors, colleagues, and so on, among which, from a personal perspective, parents are the best teachers. In the second paragraph, she brought up her first sub-thesis, namely, "parents are the most devoted teachers in educating children but ask for nothing in return", where the most devoted and educating children echoed the concepts of the best and teachers.

In contrast, the weak-CTS students had trouble comprehending key concepts of the writing topic and their conceptual relationship. As a result, they used an inappropriate writing style or digressed from the topic, whereas the five strong-CTS students were not observed to do so. Three weak-CTS students chose a prose style for their writing. For instance, Lavender described her experience of growing up to illustrate why parents are the best teachers in her eyes. She wrote, "First of all, I am the lucky girl who was born surrounded by love. My parents did everything out of love [so] that I could grow up happily... they gave me comfort and satiety when I was hungry, sleepy or angry...They told stories every night; they cooed to me if I did something wrong, or they indulged me in kissing that I was pretty sure family is love." Canna agreed that parents are the best teachers, but she devoted nearly two fifths of her essay to talking about the value of education and parental preparation for child education, which was off track and impertinent to the thesis she should have supported. When she took the chance to argue for her thesis, she just wrote one paragraph saying that parents are the first teachers in our lives. The final sentence shown below betrayed her vague understanding of the topic itself.

In conclusion, parents are the best teachers because they can teach us what we can't learn from schools or anywhere else, they make us to be a true person. Therefore, when we focus on built an educational environment for children, we need to pay great attention to parent education, too.

\subsubsection{Clarity}

Clarity of argumentative writing is determined by thesis and sub-theses formulated by the writer on the basis of summary and abstract generalization (Wen \& Liu, 2006). Reading through the selected essays left an impression that the weak-CTS students were not quite adept at summarizing and generalizing. In her second paragraph given below, Ivy mentioned the importance of parents by comparing them to a mirror, and then explained why parents are the best teachers, but failed to extract a forceful sub-thesis like "parents teach us the most essential things in our life" to guide readers through this paragraph.

The importance of parents cannot be emphasized any more. For young and naive children, their parents like a mirror. Children always imitate their parents because they hold the belief that parents do only right things. Almost all the virtues, like honest, brave, hardworking, should children learn first from their parents. They with great patience pass down the essential knowledge that we need in order to join the real world.

The weak-CTS students also tended to write at will without a clear idea of what they were going to convey. For example, Clover concluded her essay as follows. Prior to the concluding paragraph, she uttered that parents are the best teachers, for they have taught her the basic things: live and think independently. In the conclusion, however, she added that they still teach her something new, a point which was not made previously, seemed to be superfluous and negated an otherwise compelling ending.

Anyway, my parents are the best teachers for me. They have taught me the most important and precious things in my life and they still teach me something new. It is them that make me feel I am an adult and I can live and think independently. 
The strong-CTS students illustrated their awareness of designing a topic sentence for each body paragraph to express a sub-thesis. While supporting her thesis put in the first paragraph, Daisy wrote that "parents are good teachers but not the best teachers", and expressed three sub-theses via the topic sentences of the $2^{\text {nd }}, 3^{\text {rd }}$, and $4^{\text {th }}$ paragraphs: first, most parents are ordinary people who may have bad habits and qualities inevitably; another deficiency of parents as teachers is the fact that most parents lack common senses of education; in addition, most parents educate their kids emotionally. The practice of presenting topic sentences, albeit somewhat stereotyped, guided readers and impressed them with clarity and lucidity.

\title{
4.3.3 Logicality
}

Logicality, or sound logic, helps convince readers. It means whether the sub-theses are clearly-organized and sentences hung together to make a coherent piece of writing. In this regard, the strong-CTS students were better at using logical connections. In the following paragraph composed by Lily, the connective furthermore was used to elicit a new sub-thesis. Afterwards, that's the reason why expressed a causal relationship and instead of implied the adversative relation. Content of this paragraph centered around a single idea. Providing logical connections between sentences proved to be reader-friendly.

Furthermore, parents now are generally so child-centric that they give their children excessive care. Children are spoiled and conceited. That's the reason why a lot of children are losing a sense of public courtesy or sharing, love and compassion for others. From this perspective, instead of teaching their children good moral lessons, some parents indeed do harm to their children's development of characteristics.

Weak-CTS students used fewer connections to signify logic and more logical fallacies showed up in their essays. In her paragraph below, Ivy defined teacher but just took its narrow sense. What's more, the two connectives, therefore and because, were improperly used and caused confusion to readers. As the sentences were loosely patched up rather than neatly woven to be coherent, readers found it hard to make sense of the paragraph. Logicality is in part associated with students' CT ability; students with weak CT were characterized by stream of consciousness and randomly putting down their jumbled thoughts, which led to their illogicality in writing (Mu, 2016).

\begin{abstract}
Actually, the definition of "teacher" is "a person whose occupation is teaching", that means teachers can be good or bad. Parent is a relative who plays the role of leading and guardian. Therefore, no matter parents will have good or bad effect on children, we cannot deny that if parents behave well, they are the best teachers, because parents will give children the most far-reaching influence for a long time.
\end{abstract}

\subsubsection{Profundity}

Profundity is primarily concerned with whether arguments provided are sufficient enough to support sub-theses and ideas (Wen, 2012). The weak-CTS student Iris and the strong-CTS student Violet held a similar opinion, that is, not all the parents are good teachers, but their ways of argumentation were different. Their extracts are juxtaposed below for comparison. Iris identified several behavioral patterns of parents: parents addicted to playing Mahjong, scolding their children after drinking and merely caring about themselves not their children, but she stayed on the surface and her utterances such as at school, most of students who have bad habits are from a family that have bad habits sounded too absolute. Comparatively speaking, Violet listed more parental behaviors coupled with explanations. She appealed to our common sense by pointing to the fact that in childhood when our values begin to take shape we usually stay with parents and unconsciously imitate their habits and behaviors, and finally mentioned parents' lasting influence on children to echo her opinion.

From Iris: For example, if parents like to play Mahjong, they always play it day by day, night by night, how to make their children study well? At school, most of students who have bad habits are from a family that have bad habits. The parents only care about their hobbies. They couldn't care about their children. They only say, you are my future. When they drank much, they often said dirty 
words to their children, how to make their children respect them?

From Violet: When we are a child, we will spend large amount of time with our parents. Everything that our parents do can affect us, because we often unconsciously copy some of our parents' habits and styles of behavior. Some parents may have a series of bad habits, such as swear, shout at their partner, tell a lie, kick the dog, leave a mess and don't tidy up, all of these are likely to be imitated by their children. When they grow up, these bad habits will cause great harm both for themselves and for others. So, parents are not always the best teachers.

Rose, another strong-CTS student, regarded parents as the best teachers and supported her sub-theses with convincing examples including celebrity stories (Amy Chua, a Chinese American professor of Law at Yale University; Shi Tiesheng, a Chinese writer) and a public service advertisement on TV. Her well-chosen examples corresponding to the sub-theses are presented in Table 4.

Table 4. Examples provided by Rose to support her sub-theses

\begin{tabular}{|c|c|}
\hline Sub-theses & Supportive examples \\
\hline $\begin{array}{l}\text { 1. Parents are the most } \\
\text { devoted teachers. }\end{array}$ & $\begin{array}{l}\text { A book called Battle Hymn of the Tiger Mother caused heat debate in parenting. The } \\
\text { book writer, Amy Chua devoted herself into educating two daughters, and finally } \\
\text { both of them were admitted by elite universities. Not only did she make a detailed } \\
\text { learning plan for them, but also she sacrificed her leisure time and paid close } \\
\text { attention to children. The extremely strict way that Amy took remained } \\
\text { controversial, but it is undeniable the fact that parents, like Amy, educate children } \\
\text { willingly and wholeheartedly. }\end{array}$ \\
\hline
\end{tabular}

2. Parents educate Take an advertisement shown on CCTV as an example. A young mother washed children about code of mother-in-law's feet carefully though she was extremely tired after work. Having conducts, which has a seen this, the little son served his mother in the same way, which moved his mother profound significance. to tears. Based on the example above, it is quite obvious that parents' behaviors have potential influence on children.

3. Parents are the ones An excellent Chinese writer, Shi Tiesheng became depressed and bad-tempered closest to us and know us after losing feelings of legs. His mother was with him in his struggling time and best. taught him to be strong and brave in front of difficulties. It was his mother that inspired him and taught him the worth of living.

\subsubsection{Flexibility}

Flexibility refers to putting forward insightful ideas, or demonstrating an argument from multiple perspectives which reflects the breadth of thinking. In Liu's study (2005), 56 university freshmen were assigned a writing task with the familiar topic: Lose Weight or Not? The task was designed such that fatness, not slenderness most Chinese pursue, was advocated by a celebrity and individuality was preferred over appearance. Facing this topic, only $35 \%$ of the participants challenged the so-called authoritative viewpoint, and challenging authority is the first step to initiating CT.

In this study, we calculated how many participants dared to challenge the well-accepted view that parents are the best teachers. As cited by Rose in her essay, the TV advertisement telling the story of a boy ready to wash feet for his mother advocates filial piety and hints the parental influence on their children. We predicted that, influenced by this advertisement and the traditional culture of filial piety in China, most students participating in this study would concur that parents are the best teachers. It turned out that those with strong CTS challenged the view more often than their counterparts. Four strong-CTS students did not think that parents are the best teachers. Instead, four weak-CTS students deemed teachers as the best teachers; the only exception was Iris, who held an ambiguous view and wrote, "In my opinion, it is not completely true to say that parents are the best teachers...In some respects, parents are best teachers for their children...However, not all of the parents are good parents, good teachers for their children..."

Furthermore, the weak-CTS students did not argue flexibly or give alternative explanations. They all mentioned that parents are their first teachers, and teach them the basic things such as talking, walking, and even writing, 
which was repetitive and monotonous. The strong-CTS students, however, were able to think differently and argue with ingenious ideas. For example, while conceding that "parents are our first teachers and accompany us for the longest time", Jasmine claimed that "this very intimacy prevents parents from being our best teachers". To support this thesis, she offered three reasons: parents may protect their children excessively, pass their faulty values to them and cannot evaluate them objectively. Attached below is how she elaborated her second reason. Finally, she restated that parents are not the best teachers, though "they play irreplaceable roles in our growth and education". She also took one step further by saying that "we are taught by families, schools, books and so on, but what teaches us best is the life itself, where we fall down and stand up again and again."

[Parents] are our most respectful elders and closest families; we usually accept their values and believe that they are right. Still, parents, the faulty people, also have discrimination and outdated viewpoints. For instance, parents who have hardly experienced intercultural communication may deliver some speech filled with regional discrimination which they learned from their elders or the rumor. These presupposed impressions are against our cultivation of critical thinking and healthy values. Beyond that, there are conflicts between parents and the rapid changeable society. Some of their conservative operating styles may not fit in the present creative and personalized society any longer.

\section{Conclusion}

This study assessed the association between CTS and EFL argumentative writing of undergraduate English majors in China. The findings showed that English majors did not possess strong CTS, and that there was no significant difference in CTS across three grades. Although their CTS was not significantly correlated with EFL argumentative writing performance, which may be caused by not controlling for participants' EFL proficiency, textual analysis of typical essays indicated that strong-CTS learners outperformed weak-CTS ones in relevance, clarity, logicality, profundity and flexibility of EFL argumentative writing.

The results of this study have the main implications for EFL writing teachers to integrate CT-oriented activities into their instruction. CT should be part of any instructional practice in higher education. Since undergraduate English majors are not so strong in CTS as desired, and learners with stronger CTS do better in their EFL argumentative writing than those demonstrating weak CTS, it is urgent for teachers to train learners to think critically in writing classrooms by innovating their teaching methods. Mehta and Al-Mahrouqi's (2015) study of 30 English majors at an Oman university verifies teachability of CTS in EFL contexts and various strategies are suggested to facilitate learners' use of CTS so that they may incorporate them into their writing for academic success and lifelong learning endeavors.

This study is constrained by some limitations. It just surveyed English majors from two universities of China and failed to control for participants' EFL proficiency and also their EFL writing performance via pre-tests. It attempted to compare the CTS of English majors across three grades but did not track the same group of students to see their long-term changes in CTS because of its cross-sectional nature. The lack of randomization in selecting participants is another limitation. To increase the reliability and generalizability of the results obtained, future researchers could recruit a more representative sample of EFL learners, control for confounding variables which may influence the complex process of EFL writing, and carry out longitudinal studies to accurately see how English majors' CTS develops over college years.

\section{Acknowledgments}

The study is supported by a research grant (SKCX2016004) to the first author from the Fundamental Research Funds for the Central Universities, and a National University Students' Innovation and Entrepreneurship Training Program (201610307072) to the second author from the Ministry of Education of China.

\section{Note}

CSSCI (Chinese Social Sciences Citation Index) is an interdisciplinary citation index program in China. Developed by Nanjing University since 1997 and established in 2000, this citation database covers about 500 Chinese academic journals of humanities and social sciences, and is nowadays used by leading Chinese universities as a basis for evaluation of academic achievements and promotion.

\section{References}

Ahour, T., \& Golpour, F. (2014). Type of critical thinking and EFL learners' performance on argumentative and 
descriptive writing modes. The Iranian EFL Journal, 10(6), 528-543.

Behar-Horenstein, L. S., \& Niu, L. (2011). Teaching critical thinking skills in higher education: A review of the literature. Journal of College Teaching \& Learning, 8(2), 25-41. https://doi.org/10.19030/tlc.v8i2.3554

Bernard, R. M., et al. (2008). Exploring the structure of the Watson-Glaser Critical Thinking Appraisal: One scale or many subscales? Thinking Skills and Creativity, 3(1), 15-22. https://doi.org/10.1016/j.tsc.2007.11.001

Brown, J. D. (2006). Testing in Language Programs: A Comprehensive Guide to English Language Assessment. Beijing: Higher Education Press.

Cao, Y., \& Wu, H. (2014). A survey of English majors' critical thinking skills. Overseas English, (3), 73-74.

Condon, W., \& Kelly-Riley, D. (2004). Assessing and teaching what we value: The relationship between college-level writing and critical thinking abilities. Assessing Writing, (9), 56-75. https://doi.org/10.1016/j.asw.2004.01.003

Facione, N. C., Facione, P. A., \& Sánchez, C. A. (1994). Critical thinking disposition as a measure of competent clinical judgment: The development of the California Critical Thinking Disposition Inventory. Journal of Nursing Education, 33(8), 345-350.

Gao, B. (2015). Empirical study on relationship between English majors' critical thinking skills and their second language proficiency. Journal of Jiangsu University of Science and Technology, 15(4), 98-103.

Huang, Y. (1998). On the critical thinking deficiency. Foreign Languages and Their Teaching, (7), 1.

Jin, Y., \& Fan, J. (2011). Test for English Majors (TEM) in China. Language Testing, 28(4), 589-596. https://doi.org/10.1177/0265532211414852

Liu, D. (2005). A study on critical thinking ability in English writings of college students. Foreign Language Education, 26(2), 46-51.

Luk, J., \& Lin, A. (2015). Voices without words: Doing critical literate talk in English as a second language. TESOL Quarterly, 49(1), 67-91. https://doi.org/10.1002/tesq.161

Lun, V. M. C., Fischer, R., \& Ward, C. (2010). Exploring cultural differences in critical thinking: Is it about my thinking style or the language I speak? Learning and Individual Differences, 20(6), 604-616. https://doi.org/10.1016/j.lindif.2010.07.001

Mehta, S. R., \& Al-Mahrouqi, R. (2015). Can thinking be taught? Linking critical thinking and writing in an EFL context. RELC Journal, 46(1), 23-36. https://doi.org/10.1177/0033688214555356

$\mathrm{Mu}, \mathrm{C}$. (2016). Investigating English major students' critical thinking ability in academic writing. Modern Foreign Languages, 39(5), 693-703.

Pithers, R. T., \& Soden, R. (2000). Critical thinking in education: A review. Educational Research, 42(3), 237-249. https://doi.org/10.1080/001318800440579

Qian, J. (2015). A study of critical thinking's impact on English majors' argumentative writing. Unpublished thesis, Central China Normal University, Wuhan, China.

$\mathrm{Qu}, \mathrm{W}$. (2015). Is it deficiency in reasoning ability or in systematicity of knowledge? - On issues concerning the reasoning ability of the foreign language majors. Foreign Languages in China, 12(1), 60-66.

Stapleton, P. (2001). Assessing critical thinking in the writing of Japanese university students. Written Communication, 18(4), 506-548. http://dx.doi.10.1177/0741088301018004004

Stephenson, N. S., \& Sadler-McKnight, N. P. (2016). Developing critical thinking skills using the Science Writing Heuristic in the chemistry laboratory. Chemistry Education Research and Practice, 17(1), 72-79. https://doi.org/10.1039/C5RP00102A

Tian, J., \& Low, G. D. (2011). Critical thinking and Chinese university students: A review of the evidence. Language, Culture and Curriculum, 24(1), 61-76. https://doi.org/10.1080/07908318.2010.546400

Wangensteen, S., et al. (2010). Critical thinking dispositions among newly graduated nurses. Journal of Advanced Nursing, 66(10), 2170-2181. https://doi.org/10.1111/j.1365-2648.2010.05282.x

Watson, G., \& Glaser, E. M. (2008). Watson-Glaser Critical Thinking Appraisal Short Form Manual. Upper Saddle River, NJ: Pearson Education. 
Wen, Q. (2012). A Study on the Critical Thinking Ability of Chinese University Students Majoring in Foreign Languages. Beijing: Foreign Language Teaching and Research Press.

Wen, Q., \& Liu, R. (2006). An exploratory study on features in English majors' abstract thinking in English argumentative compositions. Journal of Foreign Languages, (2), 49-58.

Wen, Q., Zhang, L., \& Sun M. (2014). Are foreign language majors inferior to the other majors in critical thinking? Modern Foreign Languages, 37(6), 794-804.

Wen, Q., et al. (2010). A comparative study of critical thinking skills between English and other liberal arts majors. Foreign Language Teaching and Research, 42(5), 350-355.

Yang, J., \& Wu, H. (2016). An empirical study on the effects of content knowledge and critical thinking on ESL writing. Foreign Language World, (1), 36-43.

Yang,Y., \& Ren, J. (2016). Visualized analysis and reflection of the critical thinking research in China's foreign language education field. Foreign Language World, (3), 50-56.

Zhu, X. (2002). The application of WGCTA and CCTDI in baccalaureate nursing students of China. Unpublished thesis, Peking Union Medical College, Beijing, China.

Zhu, X., \& Shen, N. (2004). Research on the reliabilities and validities of Watson-Glaser Critical Thinking Appraisal and California Critical Thinking Disposition Inventory. Journal of Nursing Science, 19(21), 56-58.

\section{Copyrights}

Copyright for this article is retained by the author(s), with first publication rights granted to the journal.

This is an open-access article distributed under the terms and conditions of the Creative Commons Attribution license (http://creativecommons.org/licenses/by/4.0/). 